\title{
CHARACTERIZATION OF GLASS IONOMER CEMENTS STORED IN VARIOUS SOLUTIONS
}

\author{
KARAKTERIZACIJA STEKLO-IONOMERSKIH CEMENTOV, \\ SHRANJENIH V RAZLIČNIH RAZTOPINAH
}

\author{
Bojan Petrovic ${ }^{1}$, Dejan Markovic ${ }^{2}$, Sanja Kojic ${ }^{3}$, Tamara Peric ${ }^{2}$, Georges Dubourg ${ }^{4}$, Mihailo \\ Drljaca $^{4}$, Goran Stojanovic ${ }^{3}$ \\ ${ }^{1}$ University of Novi Sad, Faculty of Medicine, Department for Dentistry, Hajduk Veljkova 3, Novi Sad, 21000, Serbia \\ ${ }^{2}$ Belgrade University, Faculty of Dentistry, Department of Paediatric and Preventive Dentistry, Dr Subotica 11, Belgrade, 11000, Serbia \\ ${ }^{3}$ University of Novi Sad, Faculty of Technical Sciences, Trg Dositeja Obradovica 6, Novi Sad, 21000, Serbia \\ ${ }^{4}$ University of Novi Sad, BioSense Institute, Dr Zorana Djindjica 1, Novi Sad, 21000, Serbia
}

Prejem rokopisa - received: 2018-07-18; sprejem za objavo - accepted for publication: 2018-11-29

doi:10.17222/mit.2018.159

The aim of this work was to evaluate the nano-mechanical properties of glass ionomer materials, the ion concentrations at the surfaces in relation to the storage media and the $\mathrm{pH}$ environments using a scanning electron microscope with an energy-dispersive spectrometer (SEM/EDX). The glass-ionomer-based materials, Fuji Triage (FT), Fuji VIII (FVIII), Fuji IX GP (FIX), were analyzed. The sample comprised 45 cured cement disks. Five specimens of each tested material were placed in 3 storage solutions (saline, acidic solution with $\mathrm{pH}$ of $5.5, \mathrm{NaF}$ solution with $0.05 \%$ of fluoride). Nano-indentations were performed with a force up to $30 \mathrm{mN}$, penetration depths of 2500-2700 nm for $1 \mathrm{~d}$ and $21 \mathrm{~d}$ after setting. The EDX evaluation was carried out for each experimental disk, identifying the ions: $\mathrm{O}, \mathrm{Al}, \mathrm{Sr}, \mathrm{Si}, \mathrm{F}, \mathrm{Na}, \mathrm{P}, \mathrm{Ca}$. The level of significance was placed at $p<0.05$. The highest fluoride proportion at the specimen surface was recorded in the FT material. FT also exhibited the lowest fluoride ions content when stored in low-pH environments compared with the other tested materials $(p<0.05)$. The surface hardness of the tested materials decreased from $1.377 \mathrm{GPa}$ (in saline) to $0.03 \mathrm{GPa}$ (in acid). The Young's modulus varied from $14.35 \mathrm{GPa}$ to $0.112 \mathrm{GPa}$, depending on the material type (Fuji VIII $>$ Fuji IX>FT) $(p<0.001)$ and the storage media $(p<$ $0.001)$. Both the mechanical and cariostatic surface properties of commercially available glass ionomer materials are affected by the storage media.

Keywords: glass ionomer, nano-indentation, SE, EDX

Namen predstavljenega dela je bil ovrednotiti nanomehanske lastnosti ionomerskih steklenih materialov, ki služijo v zobni protetiki kot razna polnila. Koncentracijo ionov na površini v povezavi z medijem za shranjevanje s specifičnim pH okoljem so okarakterizirali tudi $\mathrm{z}$ uporabo vrstičnega elektronskega mikroskopa s prigrajenim energijskim disperzijskim spektroskopom (SEM/EDX). Analizirali so naslednje materiale na osnovi steklenih ionomerov: Fuji Triage (FT), Fuji VIII (FVIII) in Fuji IX GP (FIX). Vzorci so vsebovali 45 vulkaniziranih cementnih diskov. Po pet (5) vzorcev vsakega preiskovanega materiala so vstavili v tri (3) različne raztopine za shranjevanje (slano vodo, kislo raztopino s pH 5,5 in raztopino NaF s 500 ppm fluorida). Po postavitvi vzorcev so izvedli nanoindentacije (vtiskovanje nanopiramide) na vzorcih s silo do $30 \mathrm{mN}$ in nastala je globina vtiska od 2500 do $2700 \mathrm{~nm}$. Tako pripravljeni vzorci so se nato nahajali v raztopinah od enega (1) do enaindvajset (21) dni. Z EDX so določili ione: $\mathrm{O}, \mathrm{Al}, \mathrm{Sr}, \mathrm{Si}, \mathrm{F}, \mathrm{Na}, \mathrm{P}$ in $\mathrm{Ca}$ na vseh eksperimentalnih diskih. Nivo pomembnosti so postavili na p<0,05. Največji delež fluorida so zaznali na vzorcu iz FT. Ta vzorec je prav tako pokazal najnižjo vsebnost fluoridnih ionov, ko je bil shranjen $\mathrm{v}$ okolju $\mathrm{z}$ nizkim $\mathrm{pH}$ v primerjavi z drugimi preiskovanimi materiali $(\mathrm{p}<0,05)$. Trdota vzorcev na površini je padala od slanice z 1,377 GPa na 0,03 GPa v kislem mediju. Youngov modul je variiral od 14,35 GPa do 0,112 GPa, odvisno od vrste materiala (Fuji VIII $>$ Fuji IX $>$ FT) $(\mathrm{p}<0,001)$ in medija za shranjevanje $(\mathrm{p}<0,001)$. Potrjeno je bilo, da raztopine za shranjevanje vplivajo tako na mehanske kot tudi kariostatične lastnosti (nagnjenost k zobni gnilobi - kariesu) površine.

Ključne besede: stekleni ionomeri, nanoindentacija, SE, EDX

\section{INTRODUCTION}

Glass ionomer cements consist of ion-leachable glasses, water-soluble polyacrilic acid, water and monomers that are photopolymerizable, for example, hydroxyl ethyl methacrylate or photopolymerizable side chains bonded to the polyacrilic acid. ${ }^{1}$ Various glasses were investigated as the constituents of glass ionomer materials. With the introduction of the modified ratio between $\mathrm{Al}_{2} \mathrm{O}_{3}$ and $\mathrm{SiO}_{2}$ in the silicate glass, Wilson and Kent produced usable cements for dental restorative materials with polyacrylic acid. ${ }^{2}$

*Corresponding author e-mail:

bojan.petrovic@mf.uns.ac.rs
Glass ionomer materials show several advantages compared to other permanent restorative materials, such as a capacity to chemically bond to a wet dental substrate, long-term fluoride release responsible for a caries-preventive effect, biocompatibility and an inadequate thermal expansion coefficient. ${ }^{3,4}$ All these favorable properties support their valuable position in everyday clinical practice, since they meet some important criteria for the contemporary concept of the prevention, prophylaxis and treatment of dental caries. However, all these favorable properties are accompanied by some disadvantages, such as the inability to achieve a satisfactory surface polish, significant porosity and relatively poor physical properties, such as surface wear and 
brittleness when fully matured or set. ${ }^{5-8}$ When it comes to all glass-ionomer-based materials the interrelationships among the structure, surface properties, physical properties and clinical performance are still not fully clarified and reported.

The majority of contemporary dental materials absorb water, even in conditions of low humidity, and this is emphasized in very humid environments such as the oral cavity. In general, this water uptake by the restorative material has been considered as detrimental, since the contact between the cement surfaces in the early stages of maturation arrests the process of cement setting, leading to unfavorable surface damage. ${ }^{9}$

In addition, the fluctuations of the mechanical characteristics of glass ionomer cements as a consequence of water sorption are crucial for assessing their clinical performance in the oral cavity. Despite reports on the changes in the mechanical features caused by storage in aqueous solutions, the effect of the water sorption of glass-ionomer-based materials is still not fully understood. ${ }^{1,9,10}$ It has been shown that during the clinical performance of glass-ionomer-based materials in the oral environment, the degradation of glass ionomer cements can be caused by acidic attack, water sorption, erosion, and wear. All these factors cause the degradation of the cement matrix, leading to an increased surface roughness and wear rate. ${ }^{11,12}$

It has been reported that conventional glass-ionomer-based materials release sodium, fluoride, silica and calcium ions in aqueous solutions, while metal-reinforced glass ionomer cements release ionic silver as well. ${ }^{13,14}$ Ion release has also been confirmed for resinmodified glass ionomer cements. ${ }^{15}$

During the past two decades, the physical characteristics of glass-ionomer-based materials have improved as a result of an increased proportion of filler-particle loading, the incorporation of resin monomers into the cement, or both. ${ }^{16}$

The caries-preventive and antibacterial effects of glass ionomer cements have been primarily credited to the presence and availability of fluoride, but the actual fluoride amount as well as a proportion of released fluoride sufficient for achieving cariostatic and prophylactic efficacy, has not been well documented. ${ }^{4}$ The fluoride contents in glass ionomer cements vary between $10 \%$ and $23 \%$. At the same time, it has also been shown that the ability for extensive fluoride release negatively affects the physical characteristics of the glass ionomer material. ${ }^{17,18}$

Nano-indentation tests have been reported as effective methods for the measurement of the mechanical characteristics of materials, such as nanocomposites, tooth enamel and bone cement. ${ }^{19-23}$ In nano-indentation testing, the depth of the penetration beneath the analyzed sample surface is measured as the load is applied to the indenter. The shape of the load-displacement curves, which are presented in this paper, are a very useful source of information, not only for calculating the modulus and hardness of the analysed specimens, but also for the discovery of non-linear effects, if any (such as cracking or phase transformations).

The goals of the present investigation were:

- to determine the nanomechanical properties of glass ionomer materials (modulus of elasticity and hardness using the nano-indentation method) on the first day and $21 \mathrm{~d}$ after setting

- to assess the ion content of cured glass-ionomercement disks with respect to different storage solutions and various $\mathrm{pH}$ environments using a scanning electron microscope equipped with an energy-dispersive spectrometer (SEM/EDX).

\section{EXPERIMENTAL PART}

Three commercial glass-ionomer-based cements, Fuji Triage (FT, conventional glass ionomer designed primarily for pits and fissure sealing, GC Int, Tokyo, Japan), Fuji VIII (FVIII, Fuji VIII GP Capsule, resinmodified glass ionomer restorative material, GC Int Tokyo, Japan) and Fuji IX (FIX, Fuji IX GP conventional glass ionomer restorative cement, GC Int Tokyo, Japan) were evaluated in this paper.

The tested materials were prepared according to the manufacturers' recommendations, similar to our previous report. ${ }^{24}$ Capsules were activated immediately before mixing and after that placed into the amalgamator device for a $10 \mathrm{~s}$ period of mixing. Afterwards, the activated capsules were placed into the original capsule applier. All three materials were placed into Teflon molds immediately after mixing. The Teflon molds were cylindrical with a diameter of $15 \mathrm{~mm}$ and a thickness of $10 \mathrm{~mm}$. During the setting of the experimental disks, the bottom and top of each mold was roofed using glass plates and hand pressure. Acceleration of the curing reaction for the FT and FVIII was induced with photoactivation for a period of $40 \mathrm{~s}$. Regarding the FIX specimens, the disks were stored in the molds, roofed with a transparent matrix for a period of $10 \mathrm{~min}$. Immediately upon the complete setting of the materials, the disks were taken from the molds and polished using Sof-Lex discs 8691-F (3M ESPE AG, Seefeld, Germany). The polished specimens were placed into $10 \mathrm{ml}$ of deionized water and stored at $37{ }^{\circ} \mathrm{C}$ for a period no longer than $24 \mathrm{~h}$. The final experimental model comprised 45 disks ( $n=15$ specimens of each of three materials). The disks were placed into 3 different solutions, resulting in 5 disks of each material per storage medium. The first storage medium was saline, the second was an acidic solution with a $\mathrm{pH}$ of 5.5 that was made using $50 \mathrm{mmol} / \mathrm{L}$ of potassium-chloride titrated to $\mathrm{pH} 5.5$ with concentrated hydrochloric acid, while medium III was a $0.05 \%$ solution derived from sodium fluoride.

All the samples were held in three appropriate storage media at $37^{\circ} \mathrm{C}$. Before the testing the disks were 
Young Modulus

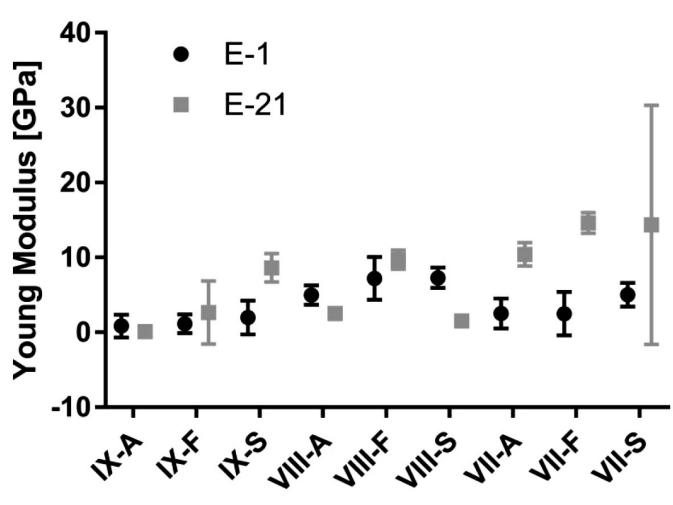

Hardness

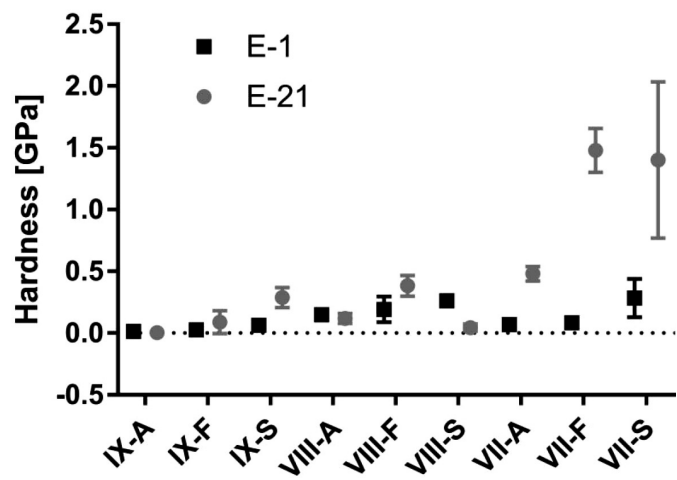

Figure 1: Young's modulus and hardness of the tested materials for 1 $\mathrm{d}$ and for $21 \mathrm{~d}$ rinsed using deionized water. A SEM/EDX examination was performed with a tabletop scanning electron microscope (TM3030, Hitachi, Tokyo, Japan) and an EDX spectrometer (Figures $\mathbf{2}$ and $\mathbf{3}$ ). The quantitative analysis of each disk was conducted at three randomly chosen spots. The ion proportion was recorded for the following ions, $\mathrm{Ca}, \mathrm{O}, \mathrm{Si}, \mathrm{F}, \mathrm{Al}, \mathrm{Ba}, \mathrm{P}$, and $\mathrm{Sr}$, and the values of $w / \%$, mass fractions were recorded. After the first set of measurements, each disk was placed in the same storage media as before the testing, and the same testing protocol was repeated after $21 \mathrm{~d}$.

For the indentation testing the prepared samples were mounted on the sample holder using adhesive tape. Multiple indentations were performed, fairly distributed throughout the entire sample surface. These tests were performed using an Agilent (Keysight) Nano indenter G200, which provides repeatable and reliable measurements. Multiple indentation (5 indentations per location and 50 location per sample were made) tests provide measurement repeatability for the mechanical properties of the analyzed samples. The system has a resolution of load and displacement of less than $50 \mathrm{nN}$ and $0.1 \mathrm{~nm}$, respectively. Nano-indentation tests were conducted with a Berkovich diamond tip, with a face angle of $65.27^{\circ}$. The calibration indents were performed on fused silica. Examination of samples was performed at room temperature and the Poisson's ratio for all the samples was set to 0.27 . The indents were located $100 \mu \mathrm{m}$ apart to avoid the influence of residual stresses from adjacent im-
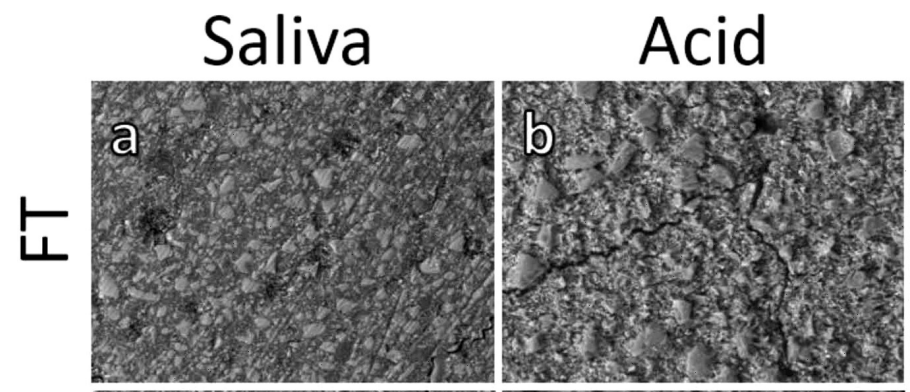

Fluoride
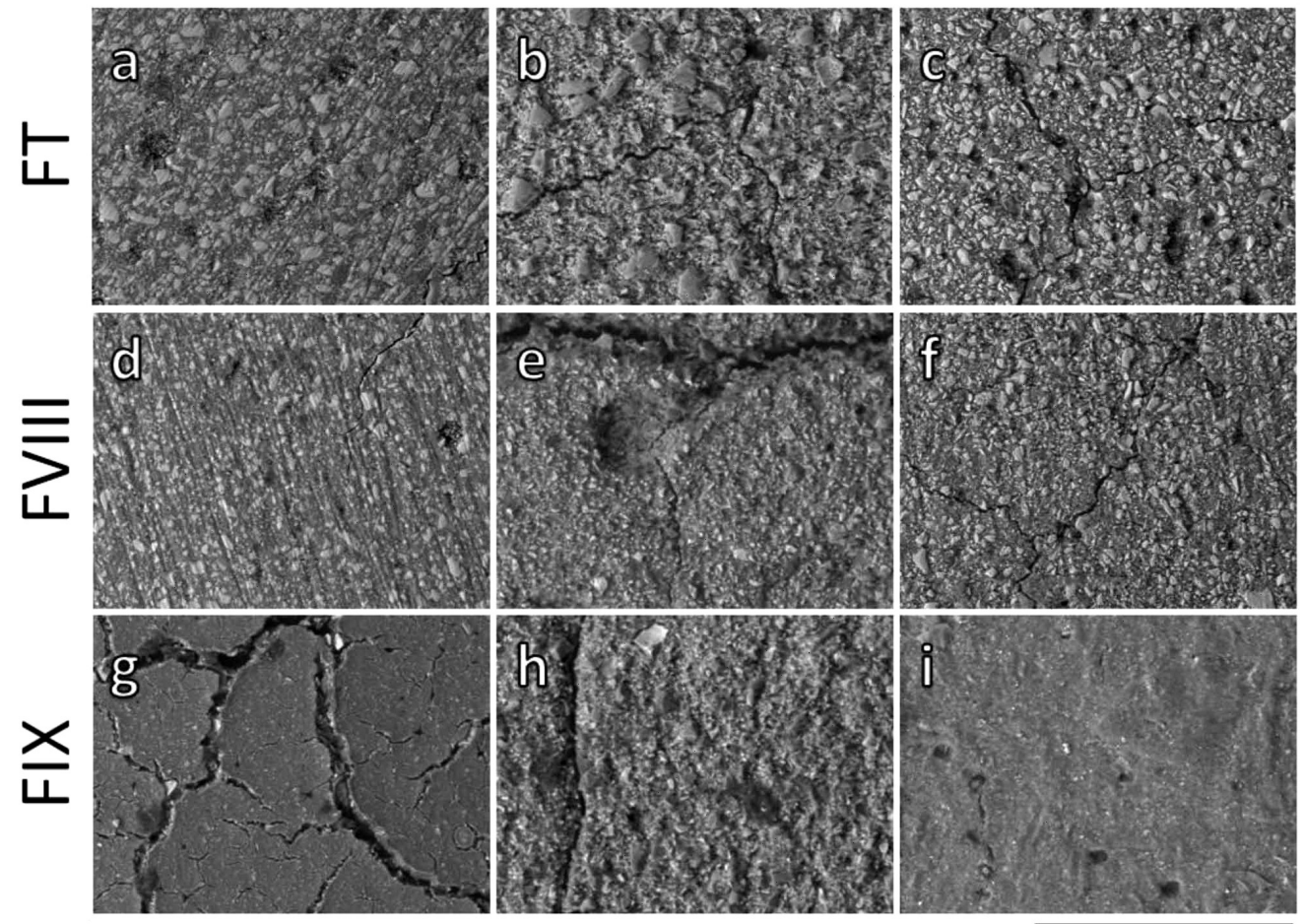

$200 \mu \mathrm{m}$

Figure 2: SE images of the tested materials' surfaces in three different storage media 
B. PETROVIC et al.: CHARACTERIZATION OF GLASS IONOMER CEMENTS STORED IN VARIOUS SOLUTIONS

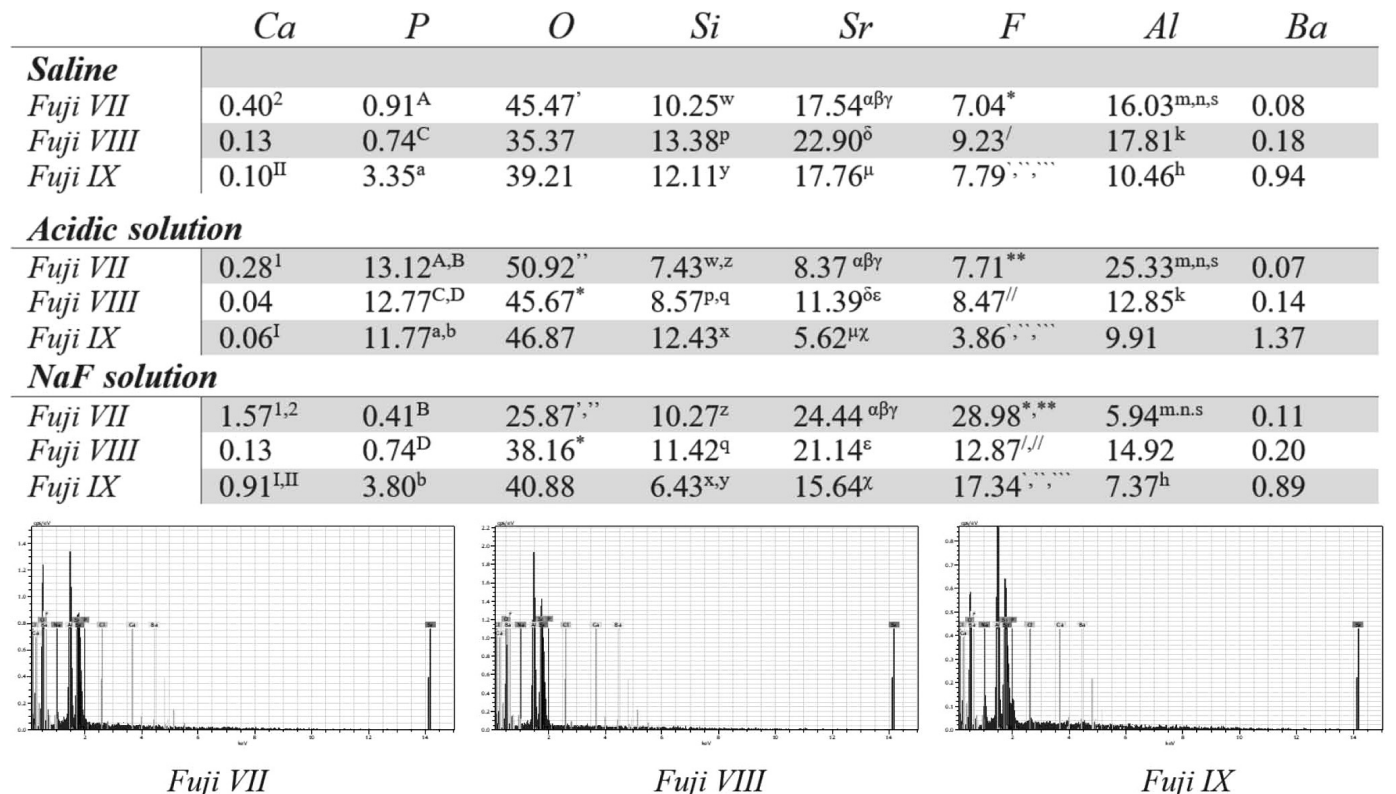

Figure 3: The elements evaluated on the experimental materials, and their amounts with respect to different storage media, in $w / \%$. Same superscripts indicate average values with statistically significant differences $(p<0.05)$.

pressions. All the tests were performed at a max load of $30 \mathrm{mN}$ with 5 indentations per place (with ascending forces of $1.875 \mathrm{mN}, 3.75 \mathrm{mN}, 7.5 \mathrm{mN}, 15 \mathrm{mN}$ and $30 \mathrm{mN}$ ), $10 \mathrm{~s}$ peak hold time and time to load of $15 \mathrm{~s}$.

All the statistical analyses was conducted by employing the Student's t-test with the level of significance for intergroup and intragroup differences set at $p<0.05$.

\section{RESULTS}

The results for the Young's modulus and the surface hardness determination for all the tested materials in three different storage media over the same time intervals are shown in Figures 1, 5, 6 and 7. Force-displacement curves for all 3 tested materials are plotted in Figures 5, 6 and 7.

The Fuji IX samples stored in saline showed significantly higher values for both the Young's modulus and the surface hardness compared to storage in acidic and fluoride solutions for 1 day. In addition, the significant decrease in the Young's modulus and the hardness in the Fuji IX was observed in an acidic environment for $21 \mathrm{~d}$, while a consistent increase regarding both the investigated parameters was observed in the samples stored in the saline and fluoride solutions $(p<0.001$ Student's t-test).

The Fuji VIII also showed significantly lower values for the Young's modulus and the surface hardness in an acidic environment compared to the saline and fluoride solutions for 1 day ( $p<0.001$ Student's t-test). In contrast to the Fuji IX, a significant increase in the Young's modulus and the hardness was observed in the fluoride solution, while these parameters decreased in the saline and acidic solutions for $21 \mathrm{~d}$.
The Young's modulus and the hardness values were the highest in the Fuji Triage specimens stored in saline for 1 day ( $p<0.001$, Student's t-test). A constant increase in both the investigated parameters was observed in the Fuji VII stored in all three different media for 21 days with the lowest values in the acidic solution and without a significant difference in these properties between the samples stored in the saline and the samples in the fluoride solution ( $p<0.001$, Student's t-test).

The Fuji VIII stored in saline exhibited significantly higher values in the Young's modulus for day 1, compared to the specimens in the other two media and the Fuji IX and Fuji Triage in all media. In contrast to that, the highest values for the hardness were recorded in the Fuji Triage samples stored in saline. After $21 \mathrm{~d}$, signifi-
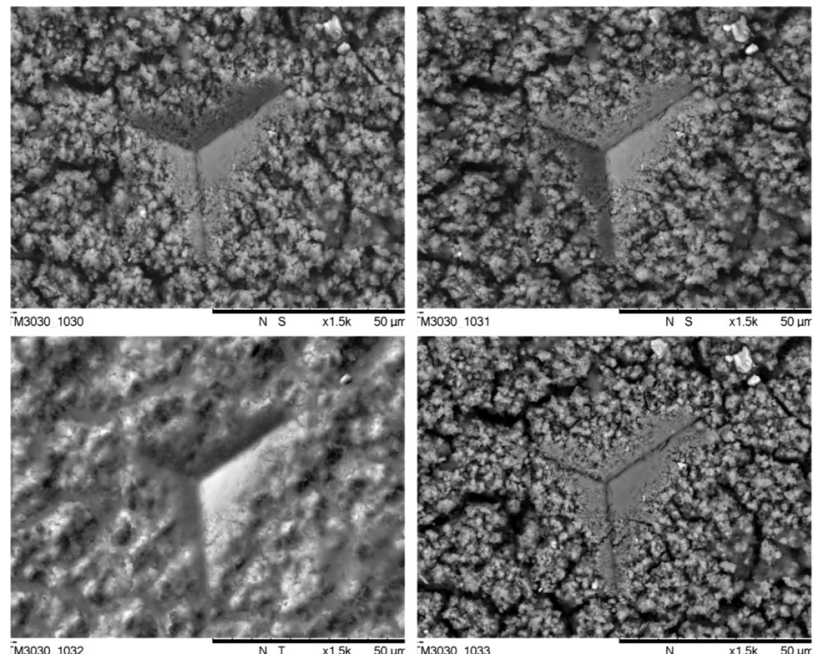

Figure 4: SE images of indentation marks in 4 different modes 
Fuji_VII-fiz: 1, 3, 5 12, 13,14, 17, 20, 35, 47

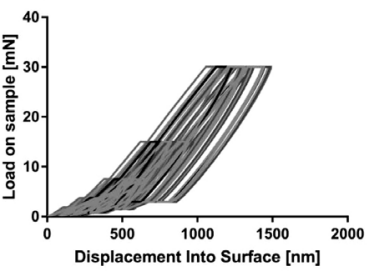

Fuji_VII-A : 17,18,19,20,21,22,35,36,37, $38,39,40,41,42,43,44$

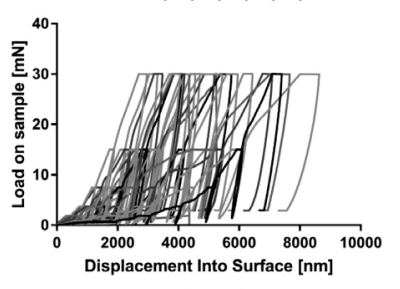

Fuji_VII-F
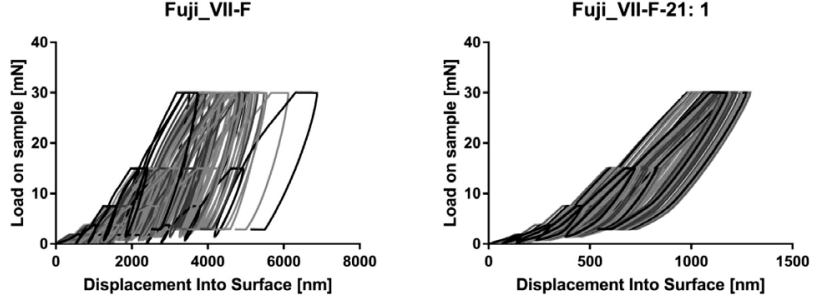

Figure 5: Load displacement curves for the Fuji Triage specimens

cantly higher values for the hardness were recorded in the Fuji Triage samples stored in the fluoride solution.

The amounts of calcium, phosphate, oxygen, silicon, strontium, fluoride, aluminum and barium ions on the study materials in $w / \%$ are shown in Figure 3. Substan-

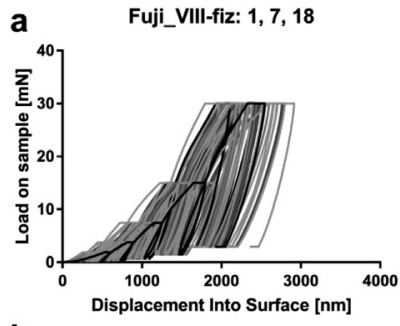

b

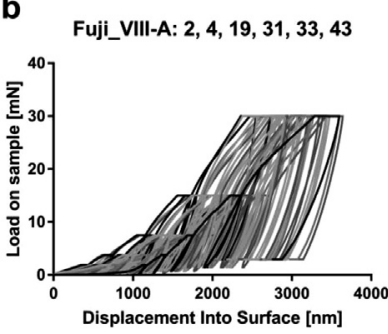

C Fuji_VIII-F: 14, 27, 28, 33

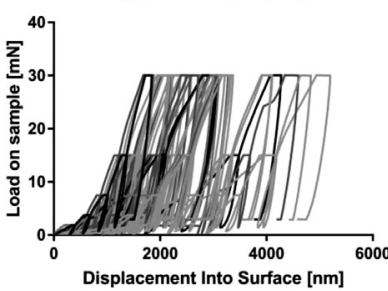

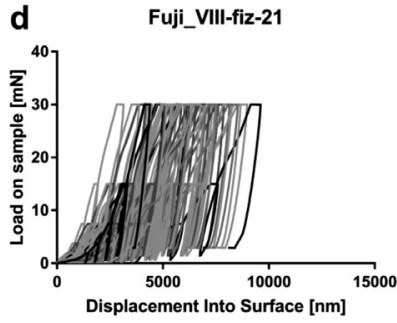$$
\text { e }
$$
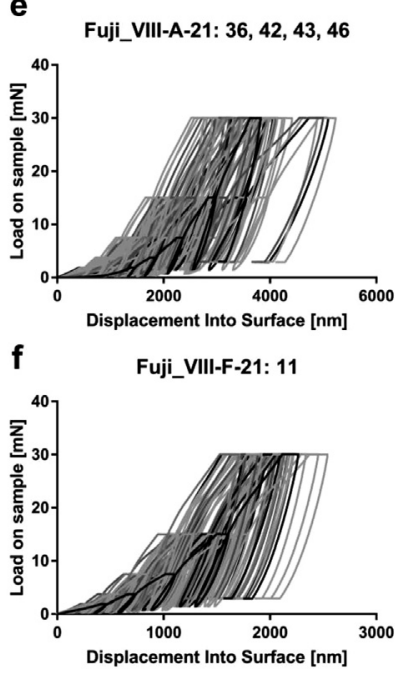

Figure 6: Load displacement curves for the Fuji VIII specimens

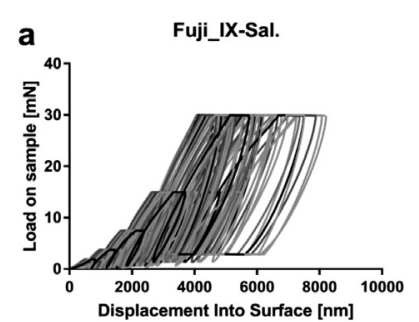

b
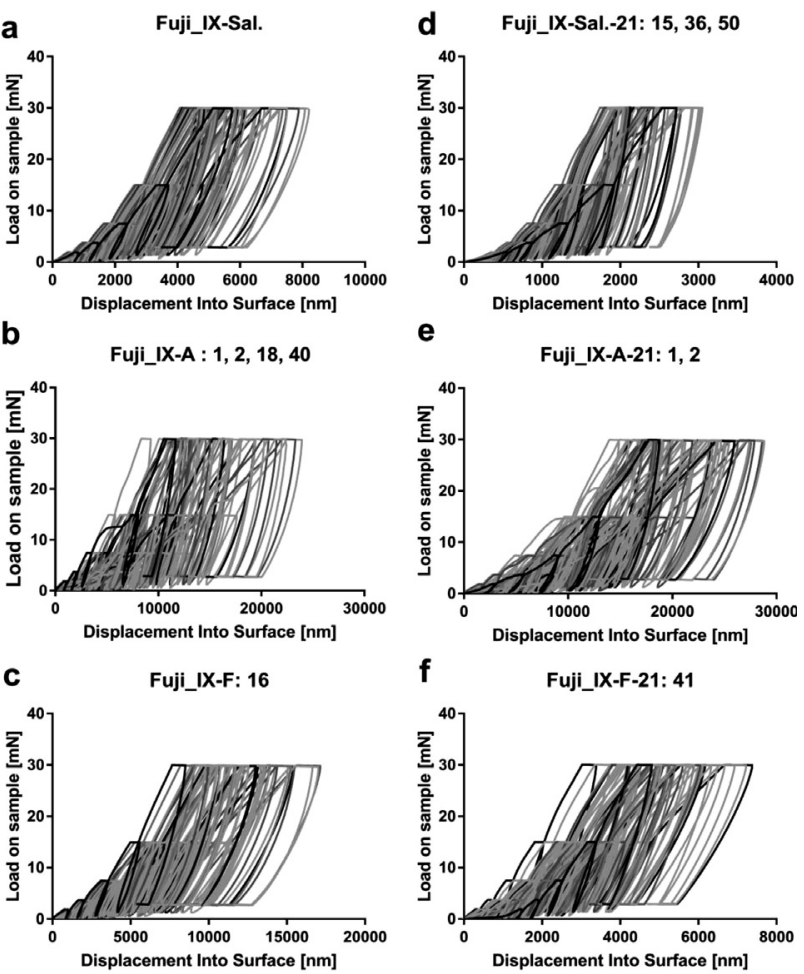

e

Fuji_IX-A-21: 1, 2

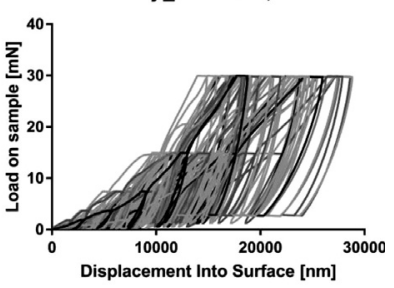

f

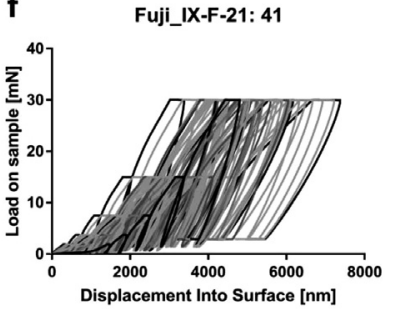

Figure 7: Load-displacement curves for the Fuji IX specimens

tially more calcium was observed in the conventional GIC-based materials immersed in the fluoride solution than in the resin-modified material. The values for phosphorus oscillated the most within all the tested materials and in all the storage media, with significantly higher values in the acidic solution. The resin-modified material showed more silicon, compared with the conventional glass ionomer materials, but this value significantly decreased in the acidic environment. On the other hand, in addition to the strontium decrease in all the materials in an acidic environment, a significant increase was observed after fluoride immersion for the Fuji Triage. Regarding the fluoride content, it has been observed that it significantly increased in all the materials after fluo-

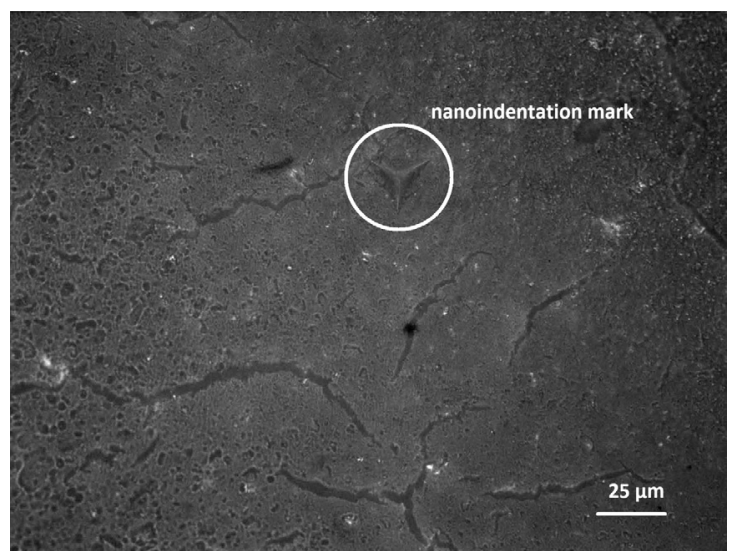

Figure 8: Profile image of the indentation mark in the glass ionomer material 
ride immersion, with significantly higher values in conventional glass ionomer materials compared to the resin-modified specimens. The values for aluminum varied significantly in all the tested materials and in all the storage media, with the highest values observed in the Fuji Triage in the acidic solution. In contrast to that, the content of barium did not show significant variations in the different storage media.

\section{DISCUSSION}

This investigation was performed to evaluate the influence of various storing solutions on the mechanical and cariostatic properties of commercially available glass ionomer materials. The property variations of dental materials during exposure to various media in the oral cavity are an important parameter when assessing their clinical performance.

In the first part of the experiment the hardness and Young's modulus of two conventional glass ionomers (FT and FIX), and one resin-modified glass ionomer (FVIII) were evaluated with respect to different storage media using the nano-indentation technique.

Large differences in the mechanical properties between the various conventional and resin-modified glass ionomer materials have been described. ${ }^{25-28}$ However, the impact of the storage media on both the physical and chemical properties of glass ionomer materials is still under discussion. In some reports it has been clearly emphasized that the obtained results regarding mechanical properties were valid only for aqueous solutions. ${ }^{27}$ Additionally, it has been shown that not only the acidity, but the type of the acid, strongly affected the properties of the glass ionomer materials. In the oral cavity, bacteria forming dental plaque, in the initial phases of caries process development, create an acidic environment that may affect the cement's physical and mechanical properties, while the topical use of fluoride is responsible for fluoride availability at the material surface..$^{29,30}$ The in vitro model employed in the current experimental study primarily focused on assessing the quantitative variations of the ion proportion only at the outer portions of three glass ionomer cements stored in acidic and neutral environments, as well as in the fluoride solution.

In the past three decades nano-indentation was used to test various specimens, including dental materials. ${ }^{25}$ Nano-indentation allows the quantification of the mechanical performances on the micro-scale. The most frequently used method to analyse the nano-indentation data is the method invented by Oliver and Pharr. ${ }^{31-34}$ It is adapted to isotropic elastoplastic materials and allows a calculation of the modulus of elasticity and the hardness. ${ }^{32}$ A nano-indentation method has been explained in which very small indentations are created using loads of only several $\mathrm{mN} .{ }^{33-35}$ Using this information it is possible to compute the hardness and the Young's modulus auto- matically from the load-displacement curve, instead of using visual measurements of the indentation impression.

The force-displacement response from both the conventional glass ionomers and the resin-modified samples are shown in Figures 4, 5, 6, 7 and 8, and it is possible to compare the tested materials directly. It has been recorded that both the hardness and the Young's modulus decreased in the acidic solution for all three tested materials, while the fluoride immersion did not affect these parameters. In a neutral environment the resinmodified glass ionomer exhibited superior mechanical properties compared to conventional glass ionomers, which is not in agreement with some previously published reports, where it has been observed that the hardness of the conventional glass ionomer material is higher than the resin-modified samples. ${ }^{26,36}$ This finding can be attributed to the different experimental protocols, storage media and techniques employed. Various mechanical properties of glass ionomer materials have been determined in numerous experimental studies, and significant variations can be observed. The obtained results are in partial agreement with the available literature data, and the obtained absolute values for the hardness and Young's modulus are lower compared to the results published in several experimental studies. ${ }^{5,37,38}$ The possible explanation for these variations is in the technique itself, because the use of nano-indentation in glass ionomer materials faces some difficulties. It is well known that glass ionomer materials consist of two completely different phases, at least on the nano scale, which can lead to some inaccuracies in the measurement.

Load-displacement curves obtained during nanoindentation tests for all the analysed samples are shown in Figures 5, 6 and 7. The curve demonstrates a smooth shape, and no pop-in could be detected. A maximum load of $30 \mathrm{mN}$ was applied to all the samples. At this maximum load, the penetration was around $350 \mathrm{~nm}$ for the Fuji VIII specimens, around $470 \mathrm{~nm}$ for the Fuji IX and around $1450 \mathrm{~nm}$ for the Fuji Triage. These results revealed that the highest hardness is measured for the Fuji VIII, after that the Fuji IX and finally the Fuji Triage. No fracture occurred in all the analysed samples. Considering the open literature, in the paper by Willems et al. posterior composites, dental ceramics for CAD/ CAM restorations, sintered porcelain, and amalgam were studied. ${ }^{20}$ Applying the indentation method, an indentation depth of 180-350 nm was achieved, depending upon the material tested, while a maximum load of 10 $\mathrm{nN}$ was applied. The glass ionomer - Fuji Triage (FT), glass carbomer - Glass Seal (CARB), resin - Ultra Seal XT Hydro (UXT), resin - Teethmate F-1 (TETM) and resin - Defence Chroma (DEFC) were tested in the study conducted by Arsenoglu et al. ${ }^{21}$ For a maximum applied force of $6 \mathrm{mN}$, the insertion range was from $700 \mathrm{~nm}$ (for UXT) to $1100 \mathrm{~nm}$ (for TETM), which is in the range of our samples Fuji IX and Fuji Triage. The authors used 
graphite nanopeletes to improve the mechanical properties of the polymer nanocomposites in their paper. ${ }^{19}$ The normal force of $0.8 \mathrm{mN}$ was used and the indentation range obtained was from $320 \mathrm{~nm}$ to $420 \mathrm{~nm}$. Our sample Fuji VIII demonstrated almost the same hardness at 0.8 nm (see Figure 6).

In the study conducted by Akashi and coworkers the changes of the mechanical strength with time were evaluated as one of the indicators of durability, and all the analysed restorative resin-modified glass ionomer cements exhibited a significant deterioration in the compressive and tensile strengths after 12 months of immersion in water. ${ }^{1}$

The ion concentrations at the surfaces of the tested materials were evaluated with respect to the various storage solutions in the second part of the experiment. The presumption was that different chemical compositions at the material's surface could affect the mechanical properties when submitted to different storage media. The caries-preventive properties of the glass-ionomerbased materials are primarily attributed to their ability to release fluoride, but the exact relationship between the fluoride ions present at the surface of the material, the exact amount of fluoride and the fluoride release for glass ionomer cements is not well documented and the importance of the understanding of $\mathrm{F}$ release in diverse storage solutions has increased during recent years. In addition to that, the kinetics of some other ions at the surface of the glass ionomer materials, such as aluminum, calcium and silicon, have gained researchers' attention, since the glass phase of contemporary glass ionomer materials contains oxides of calcium, sodium, phosphorus, and silicon in a quantity that is necessary for sufficient material surface activity. ${ }^{27,38,39}$

The outer portions of the material rather than the material itself is of particular interest, since it has been demonstrated that the concentration of fluoride is higher at the surface of the glass ionomer samples than at the core of the material. ${ }^{36}$

In a comprehensive literature review on fluoridereleasing dental restorative materials published by Wiegand et al., two mechanisms have been identified by which fluoride ions may be released from glass ionomers into different storage media and diverse environments. ${ }^{40}$ The first described is a so-called short-term reaction that encompasses fast dissolution from the outer surface into solution, and the second is described as a slower, gradual process, resulting in the constant diffusion of ions through the core of the material. It has been uniformly confirmed that the highest fluoride ion release is found in acidic environments and the lowest in saliva, and this finding could be explained by the fact that the acidity enhances the dissolution of the glass ionomer cement leading to a higher fluoride level during the acidic attack. The underlying mechanism of the fluoride kinetics under conditions with a $\mathrm{pH}$ decrease is clarified with the fact that the ratio between free (uncomplexed) fluoride to bound (complexed) fluoride was lower in the acidic environment in comparison to the neutral environment.

Regarding the fluoride content at the surfaces of the materials evaluated in the present investigation, it has been observed that it significantly increased in all the materials after fluoride immersion with significantly higher values in conventional glass ionomer materials compared to the resin-modified specimens. The results obtained in the present investigation indicate that the fluoride concentration at the material surface is under strong influence of the storage medium for all the analysed materials. Significant fluctuations at the surfaces of the tested materials were recorded. Both conventional glass ionomer materials exhibited the lowest amounts of fluoride in the acidic environment in comparison to the reference fluoride-ion concentrations recorded in saline. This is in agreement with previous findings that glass ionomer materials release more fluoride in an acidic environment, leaving fewer fluoride ions at the surface of the material, thus providing the largest amount of fluoride during the acidic attack in order to prevent caries development. ${ }^{24}$

In the present investigation it has been observed that significantly more calcium was found at the surfaces of the conventional glass ionomer cements immersed in the fluoride solution than on the resin-modified material. This finding is in agreement with the observation that calcium ions that are present in rather insoluble compounds when exposed to neutral conditions are released in an acidic environment, and that under acidic conditions, more calcium and strontium is released, too. ${ }^{41,42}$ On the other hand, in addition to the strontium decrease in all the materials in an acidic environment, a significant increase has been observed after fluoride immersion for the Fuji Triage. Apart from the release of fluoride, the strontium release is regarded as particularly important for the anti-cariogenic properties of glass ionomer materials, since it has been shown that the re-mineralizing effect of fluoride is enhanced by the presence of strontium. ${ }^{43}$ The fluoride release from the glass ionomer material is higher where some or all the calcium is replaced by strontium. ${ }^{43}$

The presence of a large number of different ions in glass-ionomer-based materials makes them able to release the majority of these ions, besides fluoride, to the immediate surroundings. It has been demonstrated that sodium, aluminum, silicon and phosphorus are released from glass-ionomer-based materials in all storage conditions, while only small amounts of calcium or strontium release have been observed under neutral conditions. ${ }^{44}$ It has been suggested that acidic conditions boost the release of all ions, causing a large proportion of calcium ions to be released. However, it has been emphasized that an enhanced release in acid is not uniform for all the ionic constituents and occurs to different extents for each ion.

The question about ion release from glass ionomer cements has been addressed in depth in studies con- 
ducted by Nicholson, Wasson and Czarnecka. Based upon the classic study of Barry et al. that described the ion releasing stoichiometry of ionomer glasses using the acetic acid model, and reported that the distribution and concentration of ions released from the glass ionomer cement were directly related to the composition of the glass, particularly to the presence of specific fluoriderich calcium fluoride phases, it has been suggested that acidic attack mainly takes place at these calcium-rich areas of the set cement surface. ${ }^{45-47}$

Like conventional glass ionomer cements, resin-modified glass ionomers release small amounts of sodium, aluminum, phosphate and silicon under neutral conditions, which has been confirmed in the present investigation..$^{42}$ The values for phosphorus varied the most within all the tested materials and in all the storage media with significantly higher values in the acidic solution. The significance of the phosphorus in the kinetics of ion release from the surface of the glass-ionomer-cement-based materials has been identified, together with its effects on the cement's working and setting time. ${ }^{48}$ But the mechanism of its effect on the glass ionomer material surface properties in relation to the different storage media needs further elucidation.

All glass ionomer materials possess their characteristics thanks to the fact that both alumina and silica are used in their formulation. ${ }^{41}$ In the present investigation the resin-modified material showed more silica on its surface than the conventional glass ionomer materials, but this value significantly decreased in an acidic environment. It has been reported that the silicon-rich layer acts as a template for calcium phosphate precipitation. ${ }^{26}$ On the other hand, the values of aluminum varied significantly in all the tested materials and in all the storage media, with the highest values observed for the Fuji Triage in an acidic solution. In contrast to that, the content of barium did not show significant variations in the different storage media.

This study faces some shortcomings that must be taken into account when the results are compared with similar studies and particularly when trying to extrapolate these results to real clinical conditions. In this paper the ion content and the mechanical properties were assessed and evaluated through changes in the tested variables at the surface of the materials investigated, while the actual values for the investigated parameters from glass ionomers into different storage media has not been obtained. In addition to that, as stated in our previous report, the surface of the material was the main point in the study, with no convincing proof that the changes at the material surface could represent the changes in the entire restoration. ${ }^{24}$ Finally, it is important to take into consideration that the different methodology used in the studies, including sample size, the media used to contain the samples, the quantity of media used to measure the surface characteristics could be responsible for the large numerical differences found among the various reports. Thus, comparisons must be made considering the behaviour of the materials, rather than the absolute numerical values for the mechanical properties and the amount of ions in absolute terms present at the surface of the material.

\section{CONCLUSIONS}

This study shows that the surface of glass ionomer materials is strongly influenced by the storage medium. The hardness and Young's modulus of both conventional and resin-modified glass ionomer materials decrease in an acidic environment, while they remain unchanged after fluoride immersion. The ion kinetics is also affected by storage media and all the tested material exhibit a satisfactory potential for the release of cariostatic elements in an acidic environment.

\section{Acknowledgment}

This work is partly supported by the project III 45021 as well as 451-111-2017/1.

\section{REFERENCES}

${ }^{1}$ A. Akashi, Y. Matsuya, M. Unemori, A. Akamine, The relationship between water absorption characteristics and the mechanical strength of resin-modified glass-ionomer cements in long-term water storage, Biomater., 20 (1999), 1573-1578

${ }^{2}$ A. Wilson, B. Kent, The glass-ionomer cement, a new translucent dental filling material, Appl. Chem. Biotechnol., 21 (2007), 313-313

${ }^{3}$ G. J. Mount, Buonocore memorial lecture glass-ionomer cements: past, present and future, Oper. Dent., 19 (1994), 82-90

${ }^{4}$ A. Wiegand, W. Buchalla, T. Attin, Review on fluoride-releasing restorative materials - fluoride release and uptake characteristics, antibacterial activity and influence on caries formation, Dent. Mater., 23 (2007) 3, 343-362

${ }^{5}$ J. Zoergiebel, N. Ilie, Evaluation of a conventional glass ionomer cement with new zinc formulation: effect of coating, aging and storage agents. 3. Clin. Oral. Investig., 17 (2013) 2, 619-626

${ }^{6}$ M. A. Naasan, T. F. Watson, Conventional glass ionomers as posterior restorations, A status report for the American Journal of Dentistry, Am. J. Dent., 11 (1998), 36-45

${ }^{7}$ N. Ilie, R. Hickel, A. Valceanu, K. Huth, Fracture toughness of dental restorative materials. Clin. Oral. Invest., 16 (2012), 489-498

${ }^{8} \mathrm{~S}$. Sidhu, Glass-ionomer cement restorative materials: a sticky subject? Aust. Dent. J., 56 (2016), 23-30

${ }^{9}$ I. Small, T. Watson, A. Chadwick, S. Sidhu, Water sorption in resin-modified glass-ionomer cements: An in vitro comparison with other materials, Biomater., 19 (1998) 6, 545-550

${ }^{10}$ M. Yamauti, J. Giovannini, R. Caixeta, L. Soares, H. Palmieri, O. Fagundes, Fluoride release profile from different dental restorative materials using ion-selective electrode, Dent. Mater., 25 (2009) 5 , e25

${ }^{11}$ C. Turssi, A. Hara, C. Magalhães, M. Serra, A. Rodrigues, Influence of storage regime prior to abrasion on surface topography of restorative materials, J. Biomed. Mater. Res. 65B (2003) 2, 227-232

${ }^{12}$ W. Kanchanavasita, H. Anstice, H. Pearson, Water sorption characteristics of resin-modified glass-ionomer cements, Biomater., 18 (1997) 4, 343-349

${ }^{13}$ A. D. Wilson, D. M. Groffman, A. T. Kuhn, The release of fluoride and other chemical species from a glas-ionomer cement, Biomater., 6 (1985), 431-433 


\section{B. PETROVIC et al.: CHARACTERIZATION OF GLASS IONOMER CEMENTS STORED IN VARIOUS SOLUTIONS}

${ }^{14}$ N. K. Sarkar, B. El-Mallakh, R. Graves, Silver release from metal reinforced glass-ionomers, Dent. Mater., 4 (1988), 103-104

${ }^{15}$ L. E. Tam, D. McComb, F. Pulver, Physical properties of properietary light-cured lining materials. Oper. Dent., 16 (1991), 210-217

${ }^{16} \mathrm{~S}$. Mitra, Adhesion to dentin and physical properties of a light-cured glass-ionomer liner/base, J. Dent. Res., 70 (1991), 72-74

${ }^{17}$ J. D. B. Featherstone, Prevention and reversal of dental caries: role of low level fluoride, Community Dent. Oral. Epidemiol., 27 (1999), $31-40$

${ }^{18}$ C. S. Kavaloglu, S. Cildir, N. Sandalli. Compressive strength, surface roughness, fluoride release and recharge of four new fluoridereleasing fissure sealants, Dent. Mater. J., 26 (2007), 335-41

${ }^{19}$ M. Shokrieh, M. Hosseinkhani, M. Naimi-Jamal, H. Tourani, Nanoindentation and nanoscratch investigations on graphene-based nanocomposites, Polym. Test., 32 (2013), 45-51

${ }^{20}$ G. Willems, J. Celis, P. Lambrechts, M. Braem, G. Vanherle, Hardness and young's modulus determined by nanoindentation technique of filler particles of dental restorative materials compared with human enamel, J. Biomed. Mater. Res., 27 (1993), 747-755

${ }^{21}$ Z. Arslanoğlu, H. Altan, E. Kale, F. Bılgıç, O. Şahin, Nanomechanical behaviour and surface roughness of new generation dental fissure sealants, Acta Phys. Pol., 130 (2016), 388-393

${ }^{22}$ M. Ayatollahi, M. Yahya, A. Karimzadeh, M. Nikkhooyifar, A. Ayob, Effects of temperature change and beverage on mechanical and tribological properties of dental restorative composites, Mater. Sci. Eng. C, 54 (2015), 69-75

${ }^{23}$ S. Gao, B. An, M. Yahyazadehfar, D. Zhang, D. Arola, Contact fatigue of human enamel: Experiments, mechanisms and modeling, J. Mech. Behav. Biomed. Mater., 60 (2016), 438-450

${ }^{24}$ D. L. Markovic, B. B. Petrovic, T. O. Peric, Fluoride content and recharge ability of five glassionomer dental materials, BMC Oral Health, 28 (2008), 8-21

${ }^{25}$ M. R. Towler, A. J. Bushby, R. W. Billington, R. G. Hill, A preliminary comparison of the mechanical properties of chemically cured and ultrasonically cured glass ionomer cements, using nano-indentation techniques, Biomater., 22 (2001), 1401-1406

${ }^{26}$ H. Yli-Urpo, V. J. L. Lippo, T. Narhi, K. V. Pekka, Compressive strength and surface characterization of glass ionomer cements modified by particles of bioactive glass, Dent. Mater., 21 (2005), 201-209

${ }^{27}$ C. Peskersoy, O. Culha, Comparative evaluation of mechanical properties of dental nanomaterials, Journal of Nanomaterials, (2017), doi: $10.1155 / 2017 / 6171578$

${ }^{28}$ M. A. McKenziea, R. W. A. Lindenb, J. W. Nicholson, The physical properties of conventional and resin-modified glass-ionomer dental cements stored in saliva, proprietary acidic beverages, saline and water, Biomater., 24 (2003), 4063-4069

${ }^{29}$ C. Perrin, M. Persin, J. Sarrazin, A comparison of fluoride release from four glass ionomer cements, Quint. Int., 25 (1999), 603-608

${ }^{30}$ A. T. Kuhn, A. D. Wilson, The dissolution mechanism of silicate and glass-ionomer cements, Biomater., 6 (1985), 378-382

${ }^{31}$ W. C. Oliver, G. M. Pharr, An improved technique for determining hardness and elastic modulus using load and displacement sensing indentation experiments, J. Mater. Res., 7 (1992), 1564-1583
${ }^{32}$ Z. Fan, J. Y. Rho, Effects of viscoelasticity and time-dependent plasticity on nanoindentation measurements of human cortical bone, J. Biomed. Mater. Res., 67 (2003), 208-214

${ }^{33}$ M. F. Doerner, W. D. Nix, A method for interpreting the data from depth sensing indentation instruments, J. Mater. Res., 1 (1986), 601-609

${ }^{34}$ W. C. Oliver, G. M. Pharr, Measurement of hardness and elastic modulus by instrumented indentation: Advances in understanding and refinements to methodology, J. Mater. Res., 19 (2004), 3-20

${ }^{35}$ G. Willems, J. P. Celis, P. Lambrechts et al., Hardness and Young's modulus determined by nanoindentation technique of filler particles of dental restorative materials compared with human enamel, J. Biomed. Mater. Res. A, 27 (1993), 747-755

${ }^{36}$ D. Xie, W. A. Brantley, B. M. Culbertson, G. Wang, Mechanical properties and microstructures of glass-ionomer cements, Dent. Mater., 16 (2000), 129-138

${ }^{37}$ S. Crisp., B. G. Lewis, A. D. Wilson, Characterization of glass-ionomer cements 1.Long term hardness and compressive strength, J. Dent., 4 (1976), 162-166

${ }^{38}$ U. A. Yap, Y. S. Pek, P. Cheang, Physico-mechanical properties of a fast-set highly viscous GIC restorative, J. Oral Rehabil., 30 (2003), $1-8$

${ }^{39}$ V. Tzifa, A. Arhakis, Sealant retention in pits and fissures: preparation and application techniques. A literature review, Balk. J. Stom., 17 (2013), 9-17

${ }^{40}$ A. Wiegand, W. Buchalla, T. Attin, Review on fluoride-releasing restorative materials - Fluoride release and uptake characteristics, antibacterial activity and influence on caries formation, Dent. Mater., 23 (2007), 343-362

${ }^{41}$ H. Yli-Urpo, P. Vallittu, T. Närhi, A. Forsback, M. Väkiparta, Release of silica, calcium, phosphorus, and fluoride from glass ionomer cement containing bioactive glass, J. Biomater. Appl., 19 (2004), $5-20$

${ }^{42} \mathrm{H}$. Forss, Release of fluoride and other elements from light-cured glass lonomers in neutral and acidic conditions, J. Dent. Res., 72 (1993), 1257-1262

${ }^{43}$ S. Shahid, U. Hassan, R. Billington, R. Hill, P. Anderson, Glass ionomer cements: Effect of strontium substitution on esthetics, radiopacity and fluoride release, Dent. Mater., 30 (2014), 308-313

${ }^{44}$ B. Czarnecka, H. Limanowska-Shaw, R. Hatton, J. Nicholson, Ion release by endodontic grade glass-ionomer cement, J. Mater. Sci. Mater. Med., 18 (2007), 649-652

${ }^{45}$ T. Barry, D. Clinton, A. Wilson, The structure of a glass-io nomer cement and its relationship to the setting process, J. Dent. Res., 58 (1979), 1072-1079

${ }^{46}$ J. Luo, R. Billington, G. Pearson, Kinetics of fluoride release from glass components of glass ionomers, J. Dent., 47 (2009), 495-501

${ }^{47}$ L. Prentice, M. Tyas, M. Burrow, Ion leaching of a glass-ionomer glass: an empirical model and effects on setting characteristics and strength, J. Mater. Sci. Mater. Med., 18 (2007), 127-131

${ }^{48} \mathrm{~S}$. Sidhu, J. Nicholson, A review of glass-ionomer cements for clinical dentistry, J. Funct. Biomater., 7 (2016), 16 